\title{
Strategic Planning and the Marketing Effectiveness Audit
}

\author{
By Mark Anthony Camilleri' ${ }^{1}$, PhD (Edinburgh)
}

This is a pre-publication version of a chapter that was accepted by Springer Nature.

How to Cite: Camilleri, M. A. (2018). Strategic Planning and the Marketing Effectiveness Audit. In Travel Marketing, Tourism Economics and the Airline Product (Chapter 7, pp. 117135), Cham, Switzerland: Springer Nature.

\begin{abstract}
The central role of marketing stems from identifying processes which create value to customers. Therefore, the marketing strategies and plans should be based on relevant frameworks which create and capture value to customers and to the businesses, themselves. The strategic planning involves a thorough analysis of the businesses' internal strengths and weaknesses, and an evaluation of opportunities and threats in the market place. The scanning of the marketing environment leads management to choose particular customers and product strategies. Therefore, strategic planners have to assess their resources, competences and capabilities, as they should determine where their company stands relative to other competitors. They are expected to evaluate strategic options and to consider alternative courses of action, including market penetration, market development, product development and diversification. This chapter outlines the different stages of strategic planning. In conclusion, it underlines the importance of conducting ongoing effectiveness audits that should analyse marketing and operational aspects.
\end{abstract}

\subsection{Introduction}

Successful organisations rely on strategic planning, organisation, leadership, implementation and control to create value. The processes of strategic planning could create value

\footnotetext{
${ }^{1}$ Department of Corporate Communication, Faculty of Media and Knowledge Sciences, University of Malta, Malta. Email: mark.a.camilleri@um.edu.mt
} 
by meeting and exceeding customer needs and by delivering benefits to them. Therefore, the strategic planning process is related to the short-term marketing and operational plans. For instance, one of the main functions of strategic planning is to identify the organisations' strengths (including customer service standards, research and development, et cetera) which can be used to take advantage of opportunities (arising from political, economic, social, technological issues) in the marketing environment. In this light, it is imperative that businesses evaluate their strategic plan and marketing processes through performance management tools and marketing effectiveness audits.

\subsection{Strategic Planning}

Strategic planning is one of the most important stages in the application of marketing, as it helps them to think ahead in a systematic way. It involves the scrutinisation of the internal and external marketing environments. Marketers are expected to have a good understanding of their companies' strengths and weaknesses. They will rely on the interactions among company executives and their functional areas, including; finance, human resources management, operations, information technology, et cetera. Their support and coordinated efforts will help the company to achieve the desired performance standards for their organisation. This causes the company to sharpen its objectives, and to better prepare for sudden developments. An effective communication of the strategic plan enables staff to know what the company is aiming to achieve, and what is expected of them.

The strategic planners support their organisations' executives, senior managers, and marketers in their decision making by setting priorities. They could focus their energy on improving internal resources, capabilities and competences (to strengthen operations), whilst ensuring that employees and other stakeholders are working in tandem toward achieving common goals. The strategic plan establishes agreements around intended outcomes. It involves ongoing assessments and adjustments of the organisations' direction, in response to changing environments. Strategic planning is a disciplined effort that produces fundamental decisions and actions. Therefore, it informs the organisation where it stands, in terms of; who it serves, what it does, and why it does it; with a focus on the future. 
The marketing managers ought to assess all aspects of the organisation's strategy in the market place (i.e. the company's products, services and markets). Marketers need to be aware of their marketing environment. Their competitors' strengths and weaknesses must be identified, as rival firms may seek differentiation possibilities or cost advantages. Therefore, marketers should continuously monitor their competitors' objectives and strategies to be able to predict their intentions.

Moreover, businesses could benefit from collaborative relationships with key partners in the distribution chain, including retailers and suppliers. With respect to these marketplace stakeholders, the firm must understand: their cost structure; expectations about margins and allocation of tasks; support and training requirements; and the nature of their relationship with the firm's competitors. The suppliers should be considered as critical collaborators in supporting the businesses' marketing strategy and tactics. They are often responsible to supply quality products (e.g. organic products to hotels, gourmet meals for inflight services, et cetera) on a reliable basis.

Very often, businesses may benefit from first-mover advantages, if they are the first entrants in the marketplace. This way, they may achieve a competitive advantage over their rivals. With such an advantage, first-movers are usually rewarded with huge profit margins and a larger market share. However, not all first-movers are rewarded. If they do not capitalise on their advantages, they may leave untapped opportunities for new entrants to penetrate the market. In this case, competitors could be more effective than the first-movers.

Businesses are increasingly shortening their planning horizons as they may face contingent issues from the external environment. For instance, marketing strategy should consider the technological context. The use of digital media has supported many businesses in their distribution and communications endeavours. However, there were firms who were lagging behind, as they were not quick enough to realise the importance of this disruptive innovation. Other macro environmental factors, include; politics, regulation, law, and social norms.

\subsection{The Strategic Plans}

A strategic plan is a document which is used to communicate the organisation's long term goals and specific objectives. It coordinates the business in its execution of activities and processes. 
A well-articulated plan aligns resources, capabilities and actions with the organisation's mission, vision and strategy. Therefore, strategic planning is concerned with the allocation of human and financial resources in the most effective pattern within the organisation. Strategic management activities transform the static plan into a workable system that provides strategic direction to decision making. Very often, the strategic plan may have to be flexible as circumstances change. There are no absolute rules regarding the right methodological frameworks for the preparation of strategic plans. However, many frameworks may have common elements, including; 1) an analysis of the internal and external environments, 2) strategy formulation in different levels across the organisation, 3) strategy execution and implementation, where the high-level plan is translated into operational planning 4) an ongoing evaluation of the plan, which may necessitate refinements and adaptations to changes in the environment.

Planning involves making choices between alternatives and is primarily a decision making activity. This is clearly evidenced in Table 7.1. The last two steps cover the control process which involves measuring and correcting actual performance. These steps ensure that the right alternatives are chosen and that effective plans are implemented. 
Table 7.1 The Planning and Control Cycle

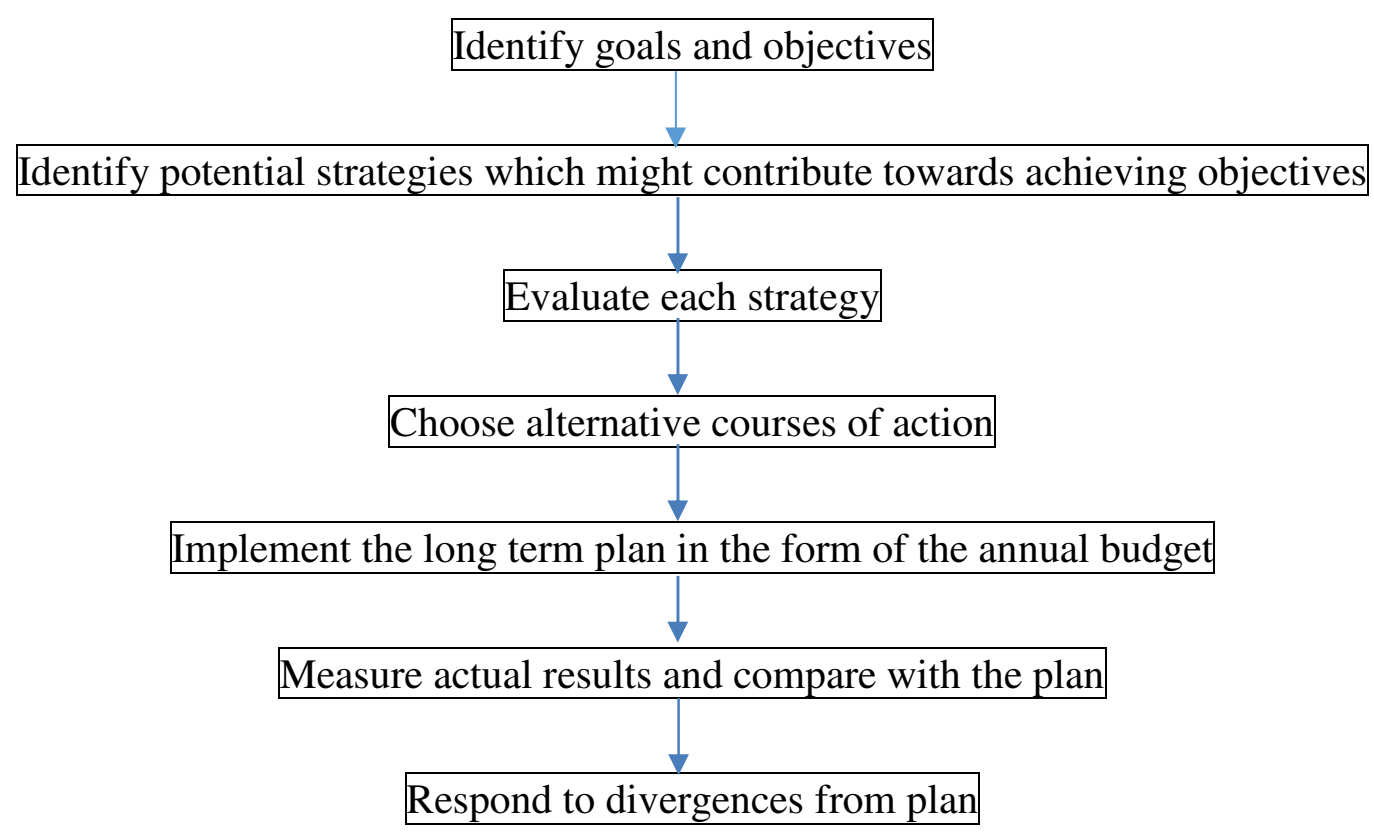

1) Identify objectives: The goals are overarching principles which guide marketers in their decision making. Businesses can plan ahead for their future, if they generate goals. Objectives are the specific steps which are required to achieve goals. These businesses' objectives are typically specific, measurable, attainable, realistic and may have an associated timeline. Objectives can be motivating to both management and employees, as meeting objectives provides a sense of accomplishment.

2) Identify potential strategies: Once an organisation has decided 'where it wants to be', the next step is to identify the possible courses of action or strategies that might enable the organisation to get there. The organisation must carry out an information gathering exercise to ensure that it has a full understanding of where it is now. This is also known as the position audit, or strategic analysis; as it involves looking inwards and outwards. A SWOT analysis will help the business to identify internal strengths and weakness within the organisation and to consider opportunities and threats in the external marketing environment. 
a) The organisation must gather information from all of its internal parts to find out: What resources it possesses? What are its capacities and capabilities? What is the state of technical know-how? How well it is able to market itself? How much cash it has in the bank?

b) It must also gather information from external sources so that it can assess its position in the environment. Just as it has assessed its own strengths and weaknesses, it must do likewise for its competitors (its threats). Current and potential markets must be analysed to identify possible opportunities. For instance, the state of the economy ought to be considered. What is likely to happen in future? Is the economy in a recession, or is it booming?

Having carried out a strategic analysis, alternative strategies can be identified. An organisation might decide to be the lowest cost producer in the industry, perhaps by withdrawing from some markets or by developing new products for sale in existing markets. This may involve internal development or a joint venture.

3) Evaluate strategies: The strategies must then be evaluated in terms of suitability, feasibility and acceptability. Management should select those strategies that have the greatest potential for achieving the organisation's objectives.

4) Choose alternative courses of action: The next step in the process is to collect the chosen strategies together and to coordinate them into a long term strategic plan.

5) Implementing the long-term plan: The strategic plan should them be broken down into smaller parts. It is unlikely that the different parts will fall conveniently into successive time periods. Strategy A may take two and a half years, while strategy B may take five months, but will not start until year three of the plan. It is usual to break down the plan as a whole into equal time periods (usually one year).

6) Measure actual results and compare with the plan: Actual results are recorded and analysed. The information about actual results is fed back to the management concerned and is often in the form of reports. This reported information is important feedback.

7) Respond to divergences from the plan: By comparing actual and planned results, management can then do one of three things, depending on how they see the situation: 
a) They can take control action. By identifying what has gone wrong and then finding out why, corrective action can be taken.

b) They can decide to do nothing. This could be the decision when actual results are going better than planned, or when poor results were caused by something which is unlikely to happen again in the future.

c) They can alter the plan or target if actual results are different from the plan or target, and there is nothing that the management can do (or nothing perhaps that they want to do) to correct the situation.

\subsection{Marketing Plans}

Short term marketing plans specify the marketing goals and objectives of businesses. They outline how resources will be used toward achieving marketing results. A detailed and calendarised plan sets out how and when marketing objectives are to be achieved; what tactics and resources will be used to achieve the desired performance, et cetera. Hence, marketing plans clarify what is expected from members of staff in marketing functions; including, product development, field sales, publicity, standards, research, public relations, distribution, and so on. They may also establish who will carry out what task, when and why. This tactical plan ensures as far as possible that the overall marketing operations are working towards achieving common goals. The marketing plans should contain the following nine items: (1) an executive summary; (2) an assessment of the current market situation; (3) a strengths, weaknesses, opportunities and threats analysis; (4) a list of objectives; (5) a specification of market research requirements; (6) a marketing strategy; (7) an action programme; (8) an outline of control and review procedures; and (9) a contingency plan.

\section{1) Executive Summary}

This is a short statement of the main goals and recommendations of the marketing plan.

\section{2) Current Market Situation}

An analysis of the current market situation can be divided into five different sections, as follows: 
Marketing situation: This consists of historical data on the size and growth of the various markets in as much detail as possible; it includes relevant information on consumer segments and market shares. Data is also presented on customer need and wants, perceptions and buying behavioural trends;

Competitive situation: Here the major competitors are described in as much detail as possible, in terms of market share, type of products, et cetera;

Distribution situation: A description of the distributive channels;

Marketing environment situation: A description of broad environmental trends (including; demographic, economic, technological, political, legal, social /cultural, and so on), which will have a bearing on the company's strategic direction. The marketing environment is continuously changing. If this was not the case, there would be no need for market planning. The marketing environment yields opportunities and threats which will surely condition the organisation's overall objectives, and consequently their marketing plans. The marketing plans will help them to respond quickly and efficiently to changes in the environment.

\section{3) Strengths, Weaknesses, Opportunities and Threats Analysis}

Endeavours should be made to identify the particular strengths and weaknesses contained within the company. The main opportunities and threats from the external environment are also identified.

\section{4) List of Objectives}

The organisational goals should be converted into statements of marketing objectives that are designed to achieve these goals (for example, an increase in sales or profitability can be achieved through: an increased brand awareness; a growing market share, the launch of new products or services, targeting new customers, the penetration into new markets; forging stakeholder relationships, improved internal communications, et cetera).

\section{5) Market Research Requirements}

At this stage, a programme of market research must be specified (for a year, at least). Earlier, this book (in Chapter 2) suggested that market research entails the systematic collection, 
analysis, interpretation and reporting of information relating to consumers, products and environmental factors which may influence the market situation.

There are two types of research - quantitative and qualitative. Quantitative research involves the statistical analysis of large numbers of people. Qualitative research explores in some depth, the reactions, opinions and behaviours of a small number of people, which are known as the sample of the population. The market research process can be divided into 4 different stages:

- The initial stage is the identification and definition of the problem and research objectives. The research objectives may be exploratory or descriptive;

- The second step entails designing the research plan. Decisions must be made here regarding the methods of data collection to be applied and the type of data to be collected (primary or secondary). The time and cost of the research must also be calculated.

- The third stage of the plan is the implementation of the research. This is the most expensive part of the process. Thus, this stage requires careful monitoring;

- The fourth stage is the analysis of the data, and the preparation of market research report with its findings and conclusions (including implications, limitations and recommendations).

It is essential that this research is carried out efficiently so that the information which it yields is accurate. As the marketing plan is based on relevant research; any inaccurate findings could distort the marketing plan.

\section{6) Strategies and Tactics within the Marketing Plan}

A broad marketing strategy or marketing mix should be given for each target market under the headings of: product, price, distribution and promotion.

In other words, a particular marketing strategy for each target market must be specified - for example, a company may target the business travellers, the leisure travellers, and so on. Afterwards, the company's overall strategic plan will identify those segments which are the most profitable, or which may be relevant to the business, for other reasons. Once it has done this, it must decide what positions it wants to occupy in these segments. This process is known as marketing positioning. It is not enough for the business to have an outstanding or an excellent 
product, if it is incorrectly positioned in its target market segments. Market positioning at its most basic level involves having an effective corporate image which appeals to the chosen customers. It must ensure that the customers appreciate the company's unique advantages over its competitors. Market positioning should contribute to the company's achievement of its overall objectives. It does this by highlighting the most appropriate areas of investment, and by identifying those market segments which will yield the highest return on investment. The company's marketing strategy can then be concentrated to improve its market share through better positioning among target segments.

\section{Market Share}

The market share which a business holds is influenced by its success, or lack of success, in terms of the positioning of its image. A badly positioned product may lead to a reduction in market share. A well-positioned product results in increased market share. The businesses must identify themselves as being one of the following: marketing leader; market holder (or challenger) or market foot holder.

The market leader has a dominant market share. Possible strategies for the market leader include: expand the market share further; expand the size of the market; protect the current market share; adopt a product innovation strategy; create a specific selling strategy; ensure efficient sales promotion, or employ heavy advertising.

The market holder (or challenger) is usually the second, third or fourth, in terms of market share. Possible strategies for the market holder include adopting a direct attack strategy which emphasises the customer benefits; the adoption of a product innovation strategy; a product variety strategy; improved service strategies; creative distribution strategies and intensive advertising strategies.

The market foot holder is a company with just a foothold in the market. Such a company may have a modest market share. The market footholder needs to get a clear picture of the market and the company's position in it. These companies should target profitable market segments. They ought to identify market needs and meet them through the application of different strategies, including: 


\section{Market Penetration}

In market penetration strategy, the organisation tries to grow by using its existing offerings (products and services) in existing markets. In other words, this will usually involve increasing the market share within existing markets. This can be achieved by selling more products or services to established customers, or by finding new customers. Here, the company will want to increase its sales for its present products in its current markets. This can be accomplished by: (i) a decrease in price; (ii) enhanced promotions and wider distribution networks; (iii) acquisition of rival businesses, in the same market; (iv) modest product refinements, among other options.

\section{Market Development}

In a market development strategy, a firm tries to expand into new markets (new cities, new destinations, new countries, et cetera) by using its existing offerings. This can be accomplished by (i) targeting different customer segments (ii) targeting new customers from other areas or regions (iv) targeting foreign markets. This strategy is more likely to be successful where the firm has a unique product technology which it can employ in a new market. In this case, the company would benefit from economies of scale, particularly, if it decides to increase its output, and if the new market is not too different from the one it has experience of. The market development strategy will only be feasible if the new market is profitable.

\section{Product Development}

This strategy suggests that a company could create new products and services for its existing markets. This involves extending the product range for the benefit of the firm's existing markets. These products may be obtained by: (i) investing in research and development of additional products; (ii) acquiring the rights to produce and sell someone else's products or services; (iii) buying new products and "branding" them; (iv) working in collaboration with other businesses, for example, through mergers and acquisitions to access new distribution channels or brands. 


\section{Diversification}

If an organisation pursues a diversification strategy, it will probably introduce new offerings, in terms of products or services, in new markets. This strategy is risky because both product and market development is required. There are different diversification strategies:

- Related diversification: This strategy involves a process that takes place when a business expands its activities in product lines that are similar to those it currently offers. For example, an established hotel chain may consider diversifying into budget accommodation.

- Concentric diversification: This strategy involves acquiring or creating new products or services to reach more consumers. The companies' new offerings are usually closely related to its existing products and services.

- Vertical integration: This strategy involves a company's expansion in its distribution chain. For example, vertical integration is conspicuous when a manufacturer owns its supplier and / or distributor. The vertical integration strategy can help companies reduce costs and improve efficiencies by decreasing transportation expenses and reducing turnaround time, among other advantages. However, at times it could be more effective for a company to rely on the established expertise and economies of scale of other vendors, rather than trying to become vertically integrated.

- Unrelated Diversification: This strategy involves introducing new or unrelated product lines or services in new markets.

Once the marketing strategies are well defined, product development may begin. Pricing may be determined, and the channels of distribution may be chosen. These activities will be employed in accordance with defined strategies, which have been formulated with the company objectives in mind. The final stage of the marketing process includes selling products and delivering the service. This involves communicating to the customers using the promotional mix (i.e. advertising, personal selling, direct marketing, sales promotion, public relations and interactive channels) in order to create awareness of, or stimulate sales of the product. The promotional mix is one of the components of the marketing mix, otherwise known as the 4Ps.

The overall amounts of money that are allocated for market penetration, market development, product development or diversification, together with their related promotional expenses, should be included in this section. 


\section{7) Action Programme}

Each element of the marketing strategy must now be elaborated in a separate section, which should answer each of the following questions: What will be done? When will it be done? Who will do it? How much will it cost?

\section{8) Control and Review Procedures}

The control and review procedures decide and outline how the plan will be controlled and monitored, once it is set in motion. (for example, what kind of feedback information is required and how often?). A date must now be set for a formal review of the plan.

Control is the final stage in the marketing planning process. It monitors the effectiveness of the marketing plan. The information provided by this control procedure forms the basis for the next round of strategic planning. If the business did not conduct an evaluation of its marketing plan, the plan would be little more than an expensive waste of time. Evaluation is a learning process. Corrective action must be taken immediately if the company realises that the plan is failing to aid it in achieving its overall objectives. A common method of carrying out such an evaluation is to conduct a marketing effectiveness audit.

Control is concerned with three things: setting standards; measuring performance and taking corrective action when performance falls too short of the stated objectives.

\section{9) Contingency Planning}

Certain control plans also contain contingency elements. A contingency plan outlines the steps to be taken in the case of specific adverse developments occurring (for example price wars, strikes, delays and so on).

\subsection{Performance Measurement}

Performance measurement aims to establish how well the business is doing in relation to a plan. Performance measures may be financial and non-financial metrics. Factors to consider include the following: 
- Measurement needs resources, including people, equipment and time to collect and analyse information. The costs and benefits of providing resources to produce a performance indicator must be carefully weighed up.

- Performance must be measured in relation to something, otherwise measurement is meaningless. Overall, performance should be measured against objectives of the organisation, and the plans that result from specific objectives. If the organisation has no clear objectives, the first step in performance measurement is to set them. The second is to identify the factors that are critical to the success of those objectives.

- Measures must be relevant. This means finding out what the organisation does and how it does it so that the measures reflect what actually occurs.

- Short or long term achievement should be measured. Short term target can be valuable, but exclusive use of them may direct the organisation away from opportunities that will mean success for the business in the long term.

- Measures should be fair. They should only include factors which managers can control by their decisions, and for which they can be held responsible.

- A variety of measures should be used. Managers may be able to find ways to distort a single measure, but should not be able to affect a variety of measures. The Balanced Score Card, the Building Blocks Model and the Performance Pyramid (see below) provide good methods of measuring performance from a number of perspectives.

- Realistic estimates may be required for measures to be employed. These include estimates of the impact of non-financial items.

- Measurement needs responses, above all. Managers will only respond to measures that they will find useful. For example, senior managers could introduce customer-centric performance metrics which measure customer acquisition, customer retention and development.

Once suitable performance measures have been selected, they must be monitored on a regular basis to ensure that they are providing useful information. There is little point in an organisation devoting resources to measuring market share if an increase in market share is not one of the organisation's objectives. 


\subsubsection{Non-Financial Performance Indicators}

One of the many criticisms of performance measurement is that they do not measure the skills, morale and training of the workforce, which can be as valuable to an organisation as its tangible assets. For example, if employees have not been trained in customer services, an organisation is unlikely to be successful. Employee attitudes and morale can be measured by surveying employees. Education and skill levels, promotion and training, absenteeism and labour turnover for the employees for which each manager is responsible can also be monitored. In many of these cases, the measures used will be non-financial ones. They may be divided into the following:

a) Measuring the quality of incoming supplies (e.g. food and beverage);

b) Monitoring employee performance (e.g. through customer surveys);

c) Measuring customer satisfaction; (e.g. letters of complaints, customer ratings, et cetera).

Service quality is usually measured by qualitative metrics, although some quantitative metrics are used, as well. The number of lost customers could be an indicator of service quality. The amount of time serving a customer could also be considered as a measure of service quality. Many hospitality and airline businesses use questionnaires to investigate the consumers' attitudes toward the service. Other possible measures of customer satisfaction in the tourism industry, include;

Market research information on consumer preferences with specific products, a number of customer complaints as a percentage of total sales volume, average time to deal with consumer queries, new customer accounts opened, and repeat business from existing customers, among others.

\subsection{The Balanced Score Card Approach}

Kaplan and Norton's (1996) Balanced Scorecard (BSC) measures organisational performance by using a balanced set of performance measures. Traditionally, companies have often used short-term financial metrics as performance measures. However, the "balanced scorecard" also includes non-financial measures to better focus on organisational performance. BSC provides 
a clear prescription as to what companies should measure in order to 'balance' the strategic and financial perspectives. The BSC approach is a strategic planning and management system that focuses on four perspectives and uses financial and non-financial indicators, as shown in Table 7.2 .

BSC connects strategic elements such as mission (the purpose), vision (aspirations), core values, strategic focus areas (themes, results and/or goals) and the more operational elements such as objectives (continuous improvement activities), non-financial measures (or key performance indicators; which track strategic performance), targets (the desired level of performance), and initiatives (projects that will help the business to reach its targets) with the traditional financial measures, including return on investments, profit margins, liquidity ratios et cetera. BSC's approach involves the continuous improvement activities and actions that will support organisations to achieve their financial, customer / stakeholder, internal process or organisational capacity (learning and growth) objectives. Generally speaking, the performance improvements in these four areas will support the organisations' strategies. For example, the objectives relating to the organisational capacity perspective will enable the business to improve its internal process perspective, which, in turn, enable the organisation to create desirable results in the customer and financial perspectives. Key performance indicators (KPIs) will be identified for each perspective and are tracked over time. The KPIs will indicate their progress toward desirable outcomes. 
Table 7.2 The Four Perspectives of the Balanced Scorecard Approach

\begin{tabular}{|c|c|c|}
\hline Perspective & Question & Explanation \\
\hline Customer (or Stakeholder) & $\begin{array}{l}\text { What do existing and new } \\
\text { customers value? }\end{array}$ & $\begin{array}{l}\text { This perspective views } \\
\text { organisational performance } \\
\text { from the point of view the } \\
\text { customer (or stakeholders). } \\
\text { It gives rise to targets that } \\
\text { matter to customers, } \\
\text { including cost, quality, } \\
\text { delivery, et cetera. }\end{array}$ \\
\hline Internal & $\begin{array}{l}\text { What processes must be } \\
\text { improved to achieve } \\
\text { marketing objectives? }\end{array}$ & $\begin{array}{l}\text { This perspective views } \\
\text { organisational performance } \\
\text { through the lenses of quality } \\
\text { and operational efficiency. } \\
\text { It is related to the } \\
\text { organisation's products or } \\
\text { services (and their internal } \\
\text { processes). }\end{array}$ \\
\hline $\begin{array}{l}\text { Organisational Capacity (or } \\
\text { Innovation and Learning) }\end{array}$ & $\begin{array}{l}\text { How can the business } \\
\text { improve further to create } \\
\text { value? }\end{array}$ & $\begin{array}{l}\text { This perspective views } \\
\text { organisational performance } \\
\text { through the lenses of human } \\
\text { capital, infrastructure, } \\
\text { technology, culture and } \\
\text { other capacities that are key } \\
\text { to breakthrough } \\
\text { performance. It considers } \\
\text { the business's capacity to } \\
\text { maintain a competitive } \\
\text { position through the } \\
\text { acquisition of new products. }\end{array}$ \\
\hline Financial (or Stewardship) & $\begin{array}{l}\text { How can the business } \\
\text { improve its financial } \\
\text { performance and its value to } \\
\text { shareholders? How can a } \\
\text { business use its financial } \\
\text { resources? }\end{array}$ & $\begin{array}{l}\text { This perspective considers } \\
\text { the organisation's financial } \\
\text { performance and its use of } \\
\text { resources. It covers } \\
\text { traditional measures such as } \\
\text { growth, profitability and } \\
\text { shareholder value. }\end{array}$ \\
\hline
\end{tabular}

\subsection{The Building Blocks Model}

Fitzgerald and Moon (1996) have developed an approach to performance measurement in business services that is based on three building blocks; including dimensions, standards and rewards, as featured in Table 7.3. 
Table 7.3 The Building Blocks Model

\begin{tabular}{|l|l|l|}
\hline Dimensions & Standards & Rewards \\
\hline Competitiveness & Ownership & Clarity \\
\hline Financial Performance & Achievability & Motivation \\
\hline Quality of Service & Fairness & Controllability \\
\hline Flexibility & & \\
\hline Resource Utilisation & & \\
\hline Innovation & & \\
\hline
\end{tabular}

The dimensions may be considered as critical success factors (or goals) for the business. Therefore, suitable metrics are used to measure the performance dimension. For example: competitiveness could be measured through relative market share; the financial performance can be measured by the profit margin; the quality of service could be determined according to product reliability; the delivery time of a product could be considered as a measure of flexibility; a metric for productivity is the utilisation of a resource, and; the degree of innovation could be ascertained according to the developments of new products.

The first two; competitiveness and financial performance relate to downstream results. The other four are upstream determinants. For example, a new product innovation will not impact on profit, cash flow and market share that were achieved in the past. However, a high level of innovation provides an indicator of how profit, cash flow and market share will move in the future. If innovation is the driver or determinant of future performance, it could also be considered a key success factor. The standards set, i.e. the KPIs, should have the following characteristics:

- Ownership: Managers who participate in the standard setting procedures are more likely to accept the standards than if they were imposed to them by others;

- Achievability: An achievable, but challenging standard is a better motivator than an unattainable one;

- Fairness: Managers should be allocated equally challenging standards.

Employees will work hard towards achieving the standards, particularly if they are motivated. The actual means of motivation may involve performance-related pay, a bonus or a promotion. The standards need to be as clear as possible. The standards should be linked to controllable 
factors. In sum, Fitzgerald and Moon's (1996) building block model could measure the key determinants of organisational performance, as their targets are set in such a way to engage and motivate staff, through ownership, achievability and fairness.

\subsection{The Performance Pyramid}

Lynch and Cross (1992) developed the performance pyramid which includes a hierarchy of financial and non-financial performance measures. Figure 7.1 illustrates how the performance pyramid links the corporate strategy with day-to-day operations. It assists in the achievement of the corporate vision.

\section{Figure 7.1 The Performance Pyramid}

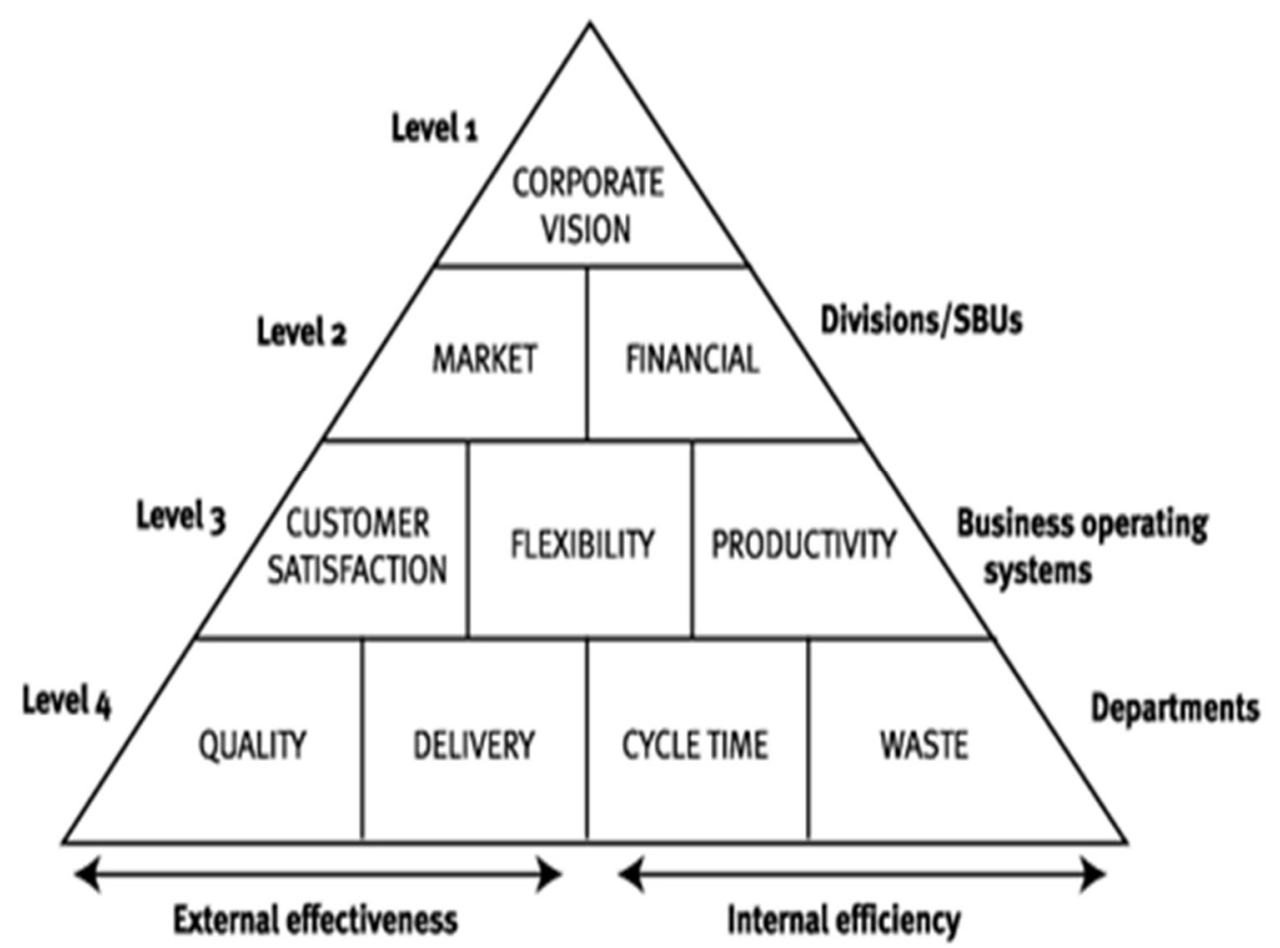

Level 1: The corporate vision or mission will help the organisation to achieve long-term success and competitive advantage.

Level 2: The focus on marketing and financial factors are critical for the achievement of corporate vision. 
Level 3: The marketing and financial strategies that were set at level 2 lead to the achievement of customer satisfaction, increased flexibility and higher productivity at the next level. These are the guiding forces behind the organisation's operations that will drive the strategic objectives of the organisation.

Level 4: The operational forces in level 3 can be monitored by using key measures, including; quality, delivery, cycle time and waste.

The left hand side of the pyramid contains measures which have an external focus and which are predominantly non-financial. Those on the right are focused on the internal efficiency of the organisation; which and are predominantly financial.

One of the drawbacks of the performance pyramid is that it focuses on two groups of stakeholders, i.e. shareholders and customers. Additional measures could be included to measure the businesses' engagement with other stakeholders.

\subsection{The Marketing Effectiveness Audit}

It is extremely important for any business to analyse its marketing effectiveness. Without measurement systems, organisations might continue to use strategies which are outdated, which do not help them achieve their corporate or marketing objectives. A marketing audit is a systematic examination of the marketing unit's objectives, strategies, organisation and performance. It has three functions, as follow:

- It identifies what the marketing unit is doing;

- It examines how it is performing these activities, and evaluates the effectiveness of these activities, in terms of the organisations' objectives and resources;

- It recommends future marketing activities.

It is important for any well-run organisation to carry out such periodic reviews of operations. This is particularly true in the field of marketing, where objectives and strategies can become quickly out-dated; as a result of changes in the environment and within the marketing organisation itself. Audits highlight trends rather than present concrete facts. They help the marketing managers to sample the effectiveness of their marketing activities. As such, they will 
not tell them how to improve or change activities. However, they highlight the strengths and weaknesses, and will show them where their decisions have been appropriate or less appropriate. An analysis of the marketing performance should be carried out to establish whether performance targets were reached. The marketing effectiveness will critically analyse the following aspects of the marketing orientation:

1) Customer Philosophy;

2) An Integrated and Effective Organisation;

3) Adequate Information;

4) Strategic Orientation;

5) Efficient Operation.

\subsubsection{The Customer Philosophy}

The customer philosophy refers to the ability of staff and management to recognise the primacy of studying the market place. It will evaluate whether management and staff are able to distinguish between different segments. There may be different opportunities that may arise from adopting a customer-centric approach.

Some managers may be technology-oriented, as they could enhance certain features of their product. Conversely, they may not embrace technology to engage with customers. There are other managers who may be sales oriented, as they believe that they would sell anything to their customers. Alternatively, managers may be driven by cost-efficiency.

\subsubsection{An Integrated and Effective Organisation}

This refers to the integration of all marketing functions towards achieving customer satisfaction. This involves using the total quality concept as a mantra throughout the entire company. Total quality can be achieved if each operating division has a clear view of customer needs. This concept suggests that the employees' priority is customer satisfaction. However, this view ought to be internalised by the members of staff in every department and must be reflected in the service they provide. It requires ongoing communications and dialogue among departments within the organisation. The information must flow freely between sections. The information communicated by one division may be critical to the operation of another. Therefore, effective channels of communication must be in place to allow the free movement 
of such information. Communication must exist all the way up from the lower levels to top echelons of management. This sort of flexibility will allow the business to service individual customer needs. This way, the customers will perceive that the company care for them. Every person and process in the business, either immediately or ultimately will affect the customer and the product. Therefore customer satisfaction is everybody's responsibility. The total quality management system requires proactive rather than reactive management as every employee should be involved from top to bottom.

\subsubsection{Adequate Information}

Marketing managers must assess whether it has relevant, up-to-date information on target markets, particularly on their customers' needs and wants. They must ensure that they receive information relating to the quality of customer service from all functional divisions which affect customer service. It is essential that there are two-way channels of communication for an organisation to function effectively.

\subsubsection{Strategic Orientation}

The businesses should have a well-defined core strategy which includes formal systems long range and short-term plans, which will consider contingency elements, if necessary.

Business demands that the future plans are under constant review and that they always contain contingency plans. A contingency plan involves making preparations to deal with problems, should they occur. For instance, airlines may have to deal with overbookings. An agreement with another airline would allow them to accommodate denied passengers who are not accepted on board. Many airlines may have interline agreements with other airlines to deal with overbooking situations.

The company's overall strategic plan defines its mission and objectives. Functional and marketing plans must also be prepared.

\subsubsection{Efficient Operations}

The businesses must ensure that appropriate resources are made available to carry out the various marketing activities. The organisations' operations involve both human and other resources (financial and technical). The companies' employees must be carefully recruited, 
assigned, trained and developed. They can achieve maximum efficiency if the human resources managers deploy them in the right areas. Different marketing strategies will require managers with different personalities and skills. Again, the total quality concept comes into play. The strategic planners must also recognise that the various operational and marketing activities must be allocated appropriate finances if they are to achieve optimum efficiency.

The marketing effectiveness audit involves the ongoing evaluation of performance against set targets, involving both quantitative and qualitative assessments. Financial and non-financial metrics can be used to examine the organisational performance, in many areas.

\subsection{Questions}

- What are the main aims of strategic planning?

- Briefly define the marketing plan

- List the nine elements which must be included in the marketing plan.

- Explain the four perspectives of the balanced score card. How can they be used to evaluate an organisation's strategic plan?

- List the five major characteristics of marketing effectiveness audits.

\subsection{Summary}

Strategic planning involves an ongoing assessment by top management of all the aspects of an organisation's strategy. Long range strategic planning includes; a definition of goals and objectives; a determination of where the company stands in the marketing environment; an evaluation of competences, resources and capabilities to put the strategic plan into action; an assessment of alternative courses of action and the strategic options available; decisions regarding possible avenues that are likely to be pursued; a preparation of other short-term plans to be conducted; the budgeting for the long term plan; the measurement of actual results and analyses; and taking necessary actions to improve the organisational performance.

The strategic planning of a company is a vital contributing factor to its long term economic performance. It guides the business by illustrating those ways in which it can most effectively 
employ its marketing resources. It also gives rise to a market plan. The marketing plan is a documented statement of marketing policies and activities. It consists of a specification of objectives (including associated goals) which will guide the businesses' marketing efforts; a presentation of resources to be used to achieve objectives and goals; and also a statement of long-term developments that may affect marketing decisions, in the short term. The marketing plan targets the most profitable segments of customers. It also communicates the positioning strategy it wants to occupy in these segments. The market share is influenced by its success, or lack of success, which a business has in positioning its image. In assessing its market share, the business must identify its position in the marketplace.

A marketing plan should contain the following nine items: an executive summary; an assessment of the current market situation; a strengths, weaknesses, opportunities and threats analysis; a list of objectives; specification of market research requirements; a marketing strategy; an action programme; outline of control and review procedures; and a contingency plan.

The monitoring and control of the market plan provides information which can be used in the next round of strategic planning. A formal system of strategic planning, if run successfully can mean the difference between a business which recognises and meets its customers' needs and wants and one which falls short of this goal. The strategic management functions ought to be measured. Factors to consider include financial and non-financial performance metrics. Managers may use a variety of measures to assess their organisational strategy; including; the Balanced Score Card, the Building Blocks Model and the Performance Pyramid.

In conclusion, it is extremely important to analyse the businesses' marketing effectiveness. A marketing effectiveness audit is a systematic examination of the marketing unit's objectives, strategies, organisation and performance. It is important for any well-run organisation to review their operations. A marketing audit relies on five major characteristics, including; customer philosophy; an integrated and effective organisation; adequate information; strategic orientation and efficient operation. 